\title{
Fat from dairy foods and 'meat' consumed within recommended levels is associated with favourable serum cholesterol levels in institutionalised older adults
}

\author{
Yusi Liu ${ }^{1}$, Shirley Poon ${ }^{1}$, Ego Seeman ${ }^{1,2}$, David L. Hare ${ }^{3}$, Minh Bui ${ }^{4}$ and Sandra Iuliano ${ }^{1 *}$ \\ ${ }^{1}$ Department of Endocrinology, University of Melbourne/Austin Health, Heidelberg, VTC 3084, Australia \\ ${ }^{2}$ Centre for Ageing, Australian Catholic University, Melbourne Campus, Fitzroy, VIC 3065, Australia \\ ${ }^{3}$ Department of Cardiology, University of Melbourne/Austin Health, Heidelberg, VIC 3084, Australia \\ ${ }^{4}$ Melbourne School of Population and Global Health, University of Melbourne, Parkville, VIC 3010, Australia
}

(Received 27 June 2018 - Final revision received 14 February 2019 - Accepted 15 February 2019)

Journal of Nutritional Science (2019), vol. 8, e10, page 1 of 8

doi:10.1017/jns.2019.5

Abstract

CVD is common in older adults. Consumption of 'meat' (beef, pork, lamb, game, poultry, seafood, eggs) and dairy foods (milk, cheese, yoghurt) is encouraged in older adults as these foods provide protein and nutrients such as essential fatty acids, Ca, Fe, Zn and vitamins A, D and $\mathrm{B}_{12}$ required for healthy ageing. However, these foods also contain saturated fats considered detrimental to cardiovascular health. To determine the effect of their consumption on CVD risk we assessed associations between fat intake from 'meat' and dairy foods and serum cholesterol levels in 226 aged-care residents (mean age 85.5 years, $70 \%$ female). Dietary intake was determined over $2 \mathrm{~d}$ using visual estimation of plate waste. Fat content of foods was determined using nutrition analysis software (Xyris, Australia). Fasting serum total cholesterol (TC), LDL-cholesterol and HDL-cholesterol were measured, and the TC:HDL-cholesterol ratio calculated. Associations were determined using random-effect models adjusted for CVD risk factors using STATA/IC 13.0. Total fat and saturated fat from 'meat' and dairy foods were associated with higher serum HDL-cholesterol levels, and dairy fat intake and number of servings were associated with a lower TC:HDL-cholesterol ratio. Every $10 \mathrm{~g}$ higher intake of fat and saturated fat from dairy products, and each additional serving was associated with a $-0.375(95 \% \mathrm{CI}-0.574,-0.175 ; P=0.0002)$, a $-0.525(95 \% \mathrm{CI}-0.834,-0 \cdot 213 ; P=0 \cdot 001)$ and a $-0 \cdot 245(95 \% \mathrm{CI}-0 \cdot 458$, -0.033; $P=0.024)$ lower TC:HDL-cholesterol ratio, respectively. Provision of dairy foods and 'meat' in recommended amounts to institutionalised older adults potentially improves intakes of key nutrients with limited detriment to cardiovascular health.

Key words: Aged-care: CVD: Dairy foods: Dietary fat: Meat food group: Saturated fat

CVD remains a leading cause of death in developed countries, with CHD and stroke accounting for $80 \%$ of all CVD deaths $^{(1)}$. In Australia, CVD accounts for the highest health care expenditure, with the greatest expenditure for people aged 65 years and over, at AU\$3923 million annually (about US $\$ 3100$ million, about $€ 2600$ million $)^{(2)}$.

Modifiable risk factors for CVD include abnormalities in serum cholesterol levels, high blood pressure, diabetes, obesity and tobacco use, with current guidelines emphasising dietary and lifestyle changes in high-risk populations ${ }^{(3)}$. However, within the aged-care setting, these guidelines can be difficult to follow by individual institutionalised older adults as they have little autonomy over food provision and preparation and the variety of lifestyle options offered. Moreover, minimal nutritional standards are not mandated so food provision is at the discretion of the provider and is, in most cases, not meeting the recommended dietary guidelines ${ }^{(4-6)}$.

Abbreviations: HDL-C, HDL-cholesterol; LDL-C, LDL-cholesterol; TC, total cholesterol.

* Corresponding author: Sandra Iuliano, fax +6139496 3365, email sandraib@unimelb.edu.au

(C) The Author(s) 2019. This is an Open Access article, distributed under the terms of the Creative Commons Attribution licence (http://creativecommons.org/licenses/by/4.0/), which permits unrestricted re-use, distribution, and reproduction in any medium, provided the original work is properly cited. 
Dietary saturated fats from animals, certain plants and manufactured foods such as crisps, cakes and biscuits probably increase the risk of CHD due to their elevating effect on serum total cholesterol (TC) and LDL-cholesterol (LDL-C) levels, potentially contributing to the development of atherosclerotic plaque ${ }^{(7,8)}$.

The Australian Dietary Guidelines recommend that women and men over the age of 70 years consume daily: 2 and 2.5 servings of foods from the 'meat' food group (lean beef, pork, lamb, game, and fish/seafood, poultry, eggs, tofu nuts/seeds) and 4 and 3.5 servings of foods from the 'dairy' food group (milk, cheese, yoghurt and/or alternatives, mostly reduced fat), respectively, as part of a healthy diet, as these foods provide protein and key nutrients, such as iodine, $\mathrm{Fe}, \mathrm{Zn}$, vitamin $\mathrm{B}_{12}$ and essential fatty acids ('meat') and $\mathrm{Ca}$, iodine, riboflavin, vitamins $\mathrm{A}, \mathrm{D}$ and $\mathrm{B}_{12}$, and $\mathrm{Zn}$ (dairy products) to support healthy ageing. Consumption of these foods at the recommended levels ensures an adequate intake of these nutrients. Furthermore, the Guidelines recommend that for older adults $>70$ years of age consumption of non-core 'discretionary' foods (e.g. crisps, cakes, biscuits) be limited to no more than 2 and 2.5 servings daily for women and men, respectively, as these foods are high in saturated fat, added sugars and salt, or alcohol ${ }^{(9)}$.

The CVD risk associated with consumption of foods in the 'meat' food group is inconsistent, possibly due to the varying fatty acid profiles of, and constituents in, the various proteinrich foods contained in this food group ${ }^{(10)}$. For example, fish contains more of the amino acid taurine while red meat contains more methionine, the former protecting against and the latter exacerbating the development of atherosclerosis in animal models $^{(11)}$. Dairy foods also have inconsistent effects on CVD outcomes, perhaps due to proteins, vitamins, minerals and other fatty acids in dairy products potentially offsetting deleterious effects of SFA via mechanisms such as interference of fat and cholesterol absorption ${ }^{(12-15)}$. Substitution of a diet high in refined carbohydrates and processed foods with a diet including both dairy foods and lean meats, such as the DASH (Dietary Approaches to Stop Hypertension) diet, resulted in reductions in blood pressure, serum cholesterol and CVD risk ${ }^{(16)}$.

Given the various fatty acid profiles and constituents in foods contained in these food groups we hypothesised that in institutionalised older adults, a higher consumption of servings of and fats from 'dairy' foods would be associated with lower serum cholesterol levels, a higher consumption of servings and fats from discretionary foods would be associated with elevated serum cholesterol levels and no association would be observed between the number of servings, or fat content of foods from the 'meat' food group and serum cholesterol levels.

\section{Methods}

\section{Study population}

Aged-care facilities in Melbourne and regional Victoria, Australia, were recruited between November 2013 and May 2014, as part of a cluster-randomised placebo-controlled trial. The inclusion criteria were: facilities were accredited with the Australian Aged-Care Quality Agency, and that accommodated predominantly ambulant residents. At baseline, informed consent was obtained from 354 residents (69.8\% females) aged 53-100 years to undergo anthropometric, dietary and nutrition assessments, and provide a fasting blood sample of which complete serum cholesterol profiles were available for 226 participants. These baseline data are reported in the present cross-sectional analysis. The overall study was approved by the Human Research Ethics Committee of Austin Health (project no. 04958) and was registered with the Australian and New Zealand Clinical Trials Registry (ACTRN 12613000228785).

\section{Assessment of food intake}

Food provided is cooked fresh on the premises and follows a 4-week menu cycle. Meals consist of a continental-style (occasionally hot) breakfast, a midday meal offering a choice between two hot dishes, and dessert, an evening meal consisting of soup and either a hot or cold food option and dessert, and three snacks daily. Guidelines for foods provision are relatively structured, e.g. meat and at least two types of vegetables offered as a hot meal option, but may vary in their content, i.e. the type of meat and vegetables offered ${ }^{(17)}$.

Food intake was determined by visual estimation of plate waste $^{(18)}$. Dietitians observed food consumption for each resident across the entire day from breakfast through to evening snacks if consumed, on two random days. A seven-point scale was used to represent the amount of food waste; $0=$ no food remaining; $+\mathrm{M}=$ mouthful remaining; $1 / 4=1 / 4$ remaining; $1 / 2=1 / 2$ remaining; $3 / 4=3 / 4$ remaining; $-\mathrm{M}=1$ mouthful consumed; $1=$ no food eaten. The relative sizes of the meals served were compared with a weighed standard meal (denoted medium), and recorded as small (75\%), medium (100\%), large $(125 \%)$, or extra-large $(150 \%)$. All components of standard serves were weighed on a digital food scale $( \pm 1 \mathrm{~g})$ (Sohnele Page Profi). This method is appropriate in this setting as it does not rely on recall or recording of foods by individuals in whom cognitive impairment is prevalent ${ }^{(6)}$.

Mean consumption of energy, macronutrients (total fats, saturated fats, monounsaturated fats, polyunsaturated fats, protein, carbohydrate), dietary fibre and minerals (Ca, Na) from all foods was calculated using Foodworks Version 7 (Xyris Software). Food composition values were derived from product-specific nutritional information on packaging. Missing nutrient values were obtained from NUTTAB 2010 ${ }^{(19)}$.

The Australian Guide to Healthy Eating is a food selection guide consisting of five food groups: fruit; vegetables; grains; dairy products; and 'meats'. Serving sizes are standard, and recommended number of servings dependent on an individual's age and sex, which if consumed in the suggested quantities ensures adequate intake of essential nutrients for good health ${ }^{(9)}$. Foods belonging to the 'dairy product' (milk, yoghurt, cheese and/or Ca-fortified plant milks) and 'meat' (lean beef, lamb, pork, game, and poultry, fish/seafood, eggs, tofu, nuts/seeds) food groups, and those classified as 'discretionary' (e.g. butter, cream, ice cream, pastries, processed meats, cakes, biscuits, spreads, soft drinks) were identified, but analysis limited to only dairy-based foods (no restriction on fat content) within 
Table 1. Characteristics of Australian elderly aged-care residents (Mean values and standard deviations; numbers and percentages)

\begin{tabular}{|c|c|c|c|}
\hline & Mean & & SD \\
\hline \multicolumn{4}{|l|}{ Sex } \\
\hline \multicolumn{4}{|l|}{ Female } \\
\hline$n$ & & 159 & \\
\hline$\%$ & & $70 \cdot 4$ & \\
\hline \multicolumn{4}{|l|}{ Male } \\
\hline$n$ & & 67 & \\
\hline$\%$ & & 29.6 & \\
\hline Age (years) & 85.7 & & 7.7 \\
\hline BMI $\left(\mathrm{kg} / \mathrm{m}^{2}\right)$ & $25 \cdot 7$ & & 4.9 \\
\hline \multicolumn{4}{|l|}{ Smoking } \\
\hline \multicolumn{4}{|l|}{ Current smoker } \\
\hline$n$ & & 12 & \\
\hline$\%$ & & $5 \cdot 3$ & \\
\hline \multicolumn{4}{|l|}{ Ex-smoker } \\
\hline$n$ & & 54 & \\
\hline$\%$ & & 23.9 & \\
\hline \multicolumn{4}{|l|}{ Non-smoker } \\
\hline$n$ & & 160 & \\
\hline$\%$ & & $70 \cdot 8$ & \\
\hline \multicolumn{4}{|l|}{ CVD } \\
\hline$n$ & & 111 & \\
\hline$\%$ & & $49 \cdot 1$ & \\
\hline \multicolumn{4}{|l|}{ IHD } \\
\hline$n$ & & 64 & \\
\hline$\%$ & & $28 \cdot 3$ & \\
\hline \multicolumn{4}{|l|}{ Cerebrovascular accident } \\
\hline$n$ & & 38 & \\
\hline$\%$ & & $16 \cdot 8$ & \\
\hline \multicolumn{4}{|l|}{ Cholesterol medication } \\
\hline$n$ & & 82 & \\
\hline$\%$ & & $36 \cdot 3$ & \\
\hline \multicolumn{4}{|l|}{ Statins } \\
\hline$n$ & & 78 & \\
\hline$\%$ & & 34.5 & \\
\hline \multicolumn{4}{|l|}{ Serum } \\
\hline Cholesterol (mmol/l) & 4.67 & & $1 \cdot 13$ \\
\hline HDL-C (mmol/l) & 1.41 & & 0.42 \\
\hline LDL-C (mmol/l) & 2.53 & & 1.03 \\
\hline TC:HDL-C ratio & 3.63 & & 1.48 \\
\hline TAG (mmol/l) & 1.60 & & 0.71 \\
\hline \multicolumn{4}{|l|}{ Nutrients* } \\
\hline Total energy intake (kJ/d) & 6605 & & 1510 \\
\hline Dairy products (servings/d) & 1.4 & & 0.8 \\
\hline Consumed milk & & & \\
\hline$n$ & & 212 & \\
\hline$\%$ & & 94 & \\
\hline Consumed cheese & & & \\
\hline$n$ & & 86 & \\
\hline$\%$ & & 38 & \\
\hline Consumed yoghurt & & & \\
\hline$n$ & & 67 & \\
\hline$\%$ & & 30 & \\
\hline Meeting recommended in & & & \\
\hline$n$ & & 5 & \\
\hline$\%$ & & 2 & \\
\hline Meat (servings/d) & $1 \cdot 2$ & & $0 \cdot 8$ \\
\hline Consumed red meat/poul & & & \\
\hline$n$ & & 201 & \\
\hline$\%$ & & 89 & \\
\hline Consumed fish & & & \\
\hline$n$ & & 90 & \\
\hline$\%$ & & 40 & \\
\hline Consumed eggs & & & \\
\hline$n$ & & 90 & \\
\hline$\%$ & & 40 & \\
\hline
\end{tabular}

Table 1. Continued

\begin{tabular}{|c|c|c|}
\hline & Mean & SD \\
\hline \multicolumn{3}{|l|}{ Meeting recommended intake } \\
\hline$n$ & \multicolumn{2}{|c|}{34} \\
\hline$\%$ & \multicolumn{2}{|c|}{15} \\
\hline Discretionary intake (servings/d) & 4.7 & $1 \cdot 1$ \\
\hline Consumed discretionary foods & & \\
\hline$n$ & \multicolumn{2}{|c|}{226} \\
\hline$\%$ & \multicolumn{2}{|c|}{100} \\
\hline \multicolumn{3}{|l|}{ Meeting recommended intake } \\
\hline$n$ & \multicolumn{2}{|c|}{27} \\
\hline$\%$ & \multicolumn{2}{|c|}{12} \\
\hline Total fat $(\mathrm{g} / \mathrm{d})$ & $66 \cdot 4$ & $20 \cdot 6$ \\
\hline Dairy products $(\mathrm{g} / \mathrm{d})$ & 11.7 & 6.6 \\
\hline Meat $(g / d)$ & $10 \cdot 7$ & 8.7 \\
\hline Discretionary foods (g/d) & $29 \cdot 3$ & 14.5 \\
\hline Saturated fat $(g / d)$ & $30 \cdot 6$ & $9 \cdot 2$ \\
\hline Dairy products $(\mathrm{g} / \mathrm{d})$ & 7.4 & 4.3 \\
\hline Meat $(g / d)$ & 3.9 & 3.3 \\
\hline Discretionary foods (g/d) & $14 \cdot 4$ & 6.9 \\
\hline Polyunsaturated fat $(\mathrm{g} / \mathrm{d})$ & $7 \cdot 3$ & 3.2 \\
\hline Monounsaturated fat $(\mathrm{g} / \mathrm{d})$ & $19 \cdot 0$ & $6 \cdot 1$ \\
\hline Protein $(g / d)$ & 55.6 & $15 \cdot 6$ \\
\hline Carbohydrate (g/d) & $192 \cdot 7$ & $51 \cdot 6$ \\
\hline Sugars $(g / d)$ & 99.0 & $34 \cdot 3$ \\
\hline Dietary fibre $(\mathrm{g} / \mathrm{d})$ & 19.4 & $7 \cdot 1$ \\
\hline $\mathrm{Ca}(\mathrm{mg} / \mathrm{d})$ & 695 & 276 \\
\hline \multicolumn{3}{|l|}{ Meeting recommended intake } \\
\hline$n$ & \multicolumn{2}{|c|}{20} \\
\hline$\%$ & \multicolumn{2}{|c|}{9} \\
\hline $\mathrm{Na}(\mathrm{mg} / \mathrm{d})$ & 2073 & 897 \\
\hline
\end{tabular}

HDL-C, HDL-cholesterol; LDL-C, LDL-cholesterol; TC, total cholesterol.

* Recommended servings for: women = dairy foods (4), 'meat' (2), discretionary foods $(0-2)$; men $=$ dairy foods (3.5), 'meat' (2.5), discretionary foods $(0-2.5)$. One serving of dairy foods $=250 \mathrm{ml}$ fresh or reconstituted powdered milk, $120 \mathrm{ml}$ evaporated milk, $40 \mathrm{~g}$ hard cheese, $120 \mathrm{~g}$ ricotta cheese, $200 \mathrm{~g}$ yoghurt. One serving of 'meat' $=65 \mathrm{~g}$ of cooked meat, $80 \mathrm{~g}$ of cooked chicken, $100 \mathrm{~g}$ of canned fish, or two eggs. One serving of discretionary foods $(600 \mathrm{~kJ} /$ serving $)=$ one tablespoon $(20 \mathrm{~g})$ butter, two tablespoons $(40 \mathrm{~g})$ cream, two scoops $(75 \mathrm{~g})$ ice-cream, $60 \mathrm{~g}$ pastries, two slices $(60 \mathrm{~g})$ processed meat, one slice $(45 \mathrm{~g})$ cake, or two to three $(40 \mathrm{~g})$ biscuits $^{(9)}$.

the 'dairy' food group and animal-based foods within the 'meat' food group. Ca-fortified plant milks (dairy food group) and tofu and nuts/seeds ('meat' food group) were excluded from analyses. However, no residents consumed Ca-fortified plant milks or tofu, but some consumed nut/seed paste (e.g. peanut butter) as a spread on toast. The majority of dairy products were full fat, in line with the Australian Guidelines that suggest whole milk is appropriate for older adults, unless medically advised otherwise. Reduced- and low-fat dairy products are infrequently used in the aged-care setting and are generally only provided to specific residents as required. Total servings per $\mathrm{d}$ of each food group were calculated using serving sizes defined by the Australian Guide to Healthy Eating. One serving of 'meat' equalled $65 \mathrm{~g}$ of cooked meat, $80 \mathrm{~g}$ of cooked chicken, $100 \mathrm{~g}$ of canned fish, or two eggs. One serving of dairy food equated to $250 \mathrm{ml}$ fresh or reconstituted powdered milk, $120 \mathrm{ml}$ evaporated milk, $40 \mathrm{~g}$ hard cheese, $120 \mathrm{~g}$ ricotta cheese, or $200 \mathrm{~g}$ yoghurt. One serving of discretionary food provided $600 \mathrm{~kJ} /$ serving, and was equivalent to one tablespoon $(20 \mathrm{~g})$ butter, two tablespoons $(40 \mathrm{~g})$ cream, two scoops $(75 \mathrm{~g})$ ice-cream, $60 \mathrm{~g}$ pastries, two slices $(60 \mathrm{~g})$ processed meat, one slice $(45 \mathrm{~g})$ cake, or two to three $(40 \mathrm{~g})$ biscuits $^{(9)}$. 
Table 2. Univariate analysis assessing association between each serum cholesterol measure and potential confounders (Coefficients with their standard errors)

\begin{tabular}{|c|c|c|c|c|c|c|c|c|c|c|c|c|}
\hline \multirow[b]{2}{*}{ Variables } & \multicolumn{3}{|c|}{ TC } & \multicolumn{3}{|c|}{ HDL-C } & \multicolumn{3}{|c|}{ LDL-C } & \multicolumn{3}{|c|}{ TC:HDL-C ratio } \\
\hline & Coefficient & SE & $P$ & Coefficient & SE & $P$ & Coefficient & SE & $P$ & Coefficient & SE & $P$ \\
\hline Female & 0.47 & 0.14 & 0.001 & 0.27 & 0.06 & $<0.001$ & 0.14 & 0.12 & 0.224 & -0.46 & 0.24 & 0.052 \\
\hline $\mathrm{Age}^{*}$ & -0.56 & 1.19 & 0.640 & 0.84 & 0.38 & 0.028 & -1.08 & 1.13 & 0.336 & -3.38 & 1.70 & 0.046 \\
\hline $\mathrm{BMI}^{*}$ & -3.05 & $1 \cdot 18$ & 0.009 & -2.95 & 0.61 & $<0.001$ & -1.61 & 1.08 & 0.137 & 5.08 & 1.73 & 0.003 \\
\hline CVD & -0.51 & 0.19 & 0.007 & -0.05 & 0.06 & 0.434 & -0.44 & 0.16 & 0.005 & -0.19 & 0.22 & 0.395 \\
\hline Diabetes & -0.16 & 0.23 & 0.491 & -0.06 & 0.07 & 0.410 & -0.20 & 0.20 & 0.309 & 0.10 & 0.28 & 0.724 \\
\hline CLM & $-1 \cdot 12$ & 0.13 & $<0.001$ & -0.07 & 0.05 & 0.186 & -1.03 & 0.13 & $<0.001$ & -0.75 & 0.21 & $<0.001$ \\
\hline Smoker & 0.55 & 0.30 & 0.069 & -0.21 & 0.11 & 0.055 & 0.57 & 0.29 & 0.054 & 1.41 & 0.57 & 0.013 \\
\hline Fish consumer* & 0.57 & $15 \cdot 6$ & 0.971 & 7.75 & 6.49 & 0.233 & 0.68 & $15 \cdot 6$ & 0.965 & -22.5 & 22.5 & 0.318 \\
\hline Total energy† & -0.22 & 0.48 & 0.656 & -0.29 & 0.17 & 0.079 & 0.10 & 0.44 & 0.823 & 0.60 & 0.72 & 0.404 \\
\hline PUFA $^{*}$ & 1.45 & 1.89 & 0.445 & -1.01 & 0.85 & 0.237 & 2.41 & 1.74 & 0.164 & 3.85 & 3.36 & 0.252 \\
\hline MUFA $^{*}$ & 0.97 & $1 \cdot 14$ & 0.395 & -0.40 & 0.47 & 0.402 & 1.26 & $1 \cdot 11$ & 0.260 & $2 \cdot 38$ & 1.70 & 0.162 \\
\hline
\end{tabular}

TC, total cholesterol; HDL-C, HDL-cholesterol; LDL-C, LDL-cholesterol; CLM, cholesterol-lowering medication; Smoker, current smoker.

* Estimated regression coefficient and standard error were multiplied by 100 .

† Estimated regression coefficient and standard error were multiplied by 10000 .

\section{Covariates}

Body weight of residents was obtained from facility documentation of monthly measured weight. Ulna length (UL) was used to estimate height using the following equation: males, height $(\mathrm{cm})=4 \cdot 605 \mathrm{UL}+1 \cdot 308$ Age $+28 \cdot 003$; females, height $(\mathrm{cm})=$ $4 \cdot 459 \mathrm{UL}+1 \cdot 315$ Age $+31 \cdot 485$, with previously demonstrated high accuracy $\left(R^{2} 0.96\right.$ and $R^{2} 0.94$, respectively) ${ }^{(20,21)}$. UL has been validated for use in elderly populations as it is less affected by ageing than standing height ${ }^{(20,22)}$. BMI was calculated using the equation weight $(\mathrm{kg}) /$ height $^{2}\left(\mathrm{~m}^{2}\right)$. Smoking status was categorised into (1) non-smoker/ex-smoker, or (2) current smoker. Medical history and medication use were recorded for each resident from medical records held at the facilities. CVD was defined as a diagnosis of CHD, cerebrovascular accident, transient ischaemic attack, peripheral artery disease and/or heart failure.

\section{Biochemistry}

Fasting morning blood samples were collected from residents at each facility by a registered pathology service (Melbourne Pathology Inc.). Blood samples were analysed for serum TC, LDL-C and HDL-cholesterol (HDL-C), using a modular analyser (Cobas 8000 C701; Roche Diagnostics) (CV 1-5 \%). TC: HDL-C ratio was generated as an additional variable using the equation TC (mmol/l)/HDL-C ( $\mathrm{mmol} / \mathrm{l})$, as it is suggested to be a more sensitive and specific CVD risk predictor compared with TC alone ${ }^{(23)}$.

\section{Statistical analysis}

Statistical analyses were conducted using STATA/IC 13.0. In this analysis dairy products were limited to milk, cheese and yogurt, and foods of animal origin in the 'meat' food group were analysed as continuous variables. Summary statistics are presented as means and standard deviations for continuous variables and sample sizes and percentages for categorical variables. The relationships between risk factors of fat (total and saturated) from dairy food and 'meats', and number of servings consumed, and the outcome variables of serum TC, HDL-C and LDL-C levels and the TC:HDL-C ratio were examined using random-effect models. This method takes into account correlation within each aged-care facility for an outcome variable.

Analyses were performed initially for each covariate to examine confounding effects. The covariates selected for this study were sex, age, BMI, diagnosis of CVD (yes/no), history of diabetes (yes/no), smoking status (current smoker, yes/no), fish consumption (yes/no), total energy, and PUFA and MUFA intake. Physical activity was not considered as this population is generally very sedentary and alcohol intake not considered as it was infrequently consumed. Those covariates with a $P$ value less than $0 \cdot 05$ were chosen to adjust for the univariate relationship between a risk factor and an outcome. Those significant univariate relationships were then examined in a multivariate model, but separately for total fat, saturated fat and type of servings. $P$ values $<0.05$ were deemed statistically significant.

\section{Results}

Characteristics of participants are presented in Table 1. Total fat intake was $64(\mathrm{sd} \mathrm{21}) \mathrm{g} / \mathrm{d}(11.5(\mathrm{SD} 6.8) \mathrm{g} / \mathrm{d}$ from the dairy food group, 10.7 (sd 8.7) g/d from the 'meat' food group and 29.3 (SD 14.4) g/d from discretionary foods), while saturated fat intake was 30 (SD 10) g/d (7.2 (SD 4.3) g/ d from the dairy food group, 3.9 (sd 3.3) g/d from the 'meat' food group and 14.4 (SD 6.9) g/d derived from discretionary foods). Mean number of servings was 1.4 (SD 0.8) from the dairy food group, 1.2 (SD 0.8 ) from the 'meat' food group and 4.7 (SD 1.1) for discretionary foods. The majority of participants did not achieve the recommended intake of servings from the dairy product $(98 \%)$ and 'meat' $(85 \%)$ food groups, and exceeded the recommended intake for discretionary foods $(88 \%)$. Individual foods within the 'dairy product' and 'meat' food groups were consumed in varying amounts. All residents consumed discretionary foods.

Associations between serum cholesterol levels and potential confounders are presented in Table 2. Smoking and higher BMI were associated with higher TC:HDL-C ratios, while diagnosis of CVD and use of cholesterol-lowering medications 
were associated with lower TC and LDL-C levels. No associations were observed between serum measures of cholesterol and dietary factors.

After adjusting for covariates (Table 2), significant relationships were observed between total and saturated fat from 'dairy products' and 'meat' and HDL-C levels (Table 3). Every $10 \mathrm{~g}$ higher intake of fat and saturated fat from dairy foods was associated with a $0.103(95 \%$ CI $0.0018,0.189)$ $\mathrm{mmol} / \mathrm{l}(P=0.018)$ and a $0.153(95 \%$ CI $0.018,0.288)$ $\mathrm{mmol} / \mathrm{l} \quad(P=0.026)$ higher HDL-C level, respectively. Corresponding associations from 'meat' were a $0.050(95 \%$ CI $0.005,0.096) \mathrm{mmol} / 1(P=0.030)$ and a $0.161(95 \% \mathrm{CI}$ $0.027, \quad 0.295) \mathrm{mmol} / \mathrm{l}(P=0.018)$ higher HDL-C level, respectively. Higher dairy total fat, saturated fat and number of servings were associated with a lower TC:HDL-C ratio. Every $10 \mathrm{~g}$ higher intake of fat and saturated fat from dairy products, and each additional serving was associated with a $-0.375(95 \%$ CI $-0.574,-0.175)(P=0.0002)$, a -0.525 $(95 \% \mathrm{CI}-0.834,-0.213)(P=0.001)$ and a $-0.245(95 \%$ CI $-0.458,-0.033)(P=0.024)$ lower TC:HDL-C ratio, respectively. No associations were observed between fat from dairy foods, meat or discretionary foods, or servings of these foods and TC and LDL-C levels. In the multivariate analyses including fat (model I) and saturated fat (model II), similar associations remained for dairy products and 'meat' total and saturated fat and serum HDL-C, and dairy fat and saturated fat and the TC:HDL-C ratio (Table 4).

\section{Discussion}

In institutionalised older adults, within recommended intake levels, higher intakes of fat or saturated fat from dairy products or 'meat' were associated with higher HDL-C levels but only dairy total fat, saturated fat and number of servings were associated with a lower TC:HDL-C ratio. Total or saturated fat from discretionary foods, or number of servings were not related to serum cholesterol levels.

The TC:HDL-C ratio is used as an atherogenic index, a lower ratio indicating lower risk ${ }^{(24)}$. A higher dairy fat intake was associated with a lower TC:HDL-C ratio, probably driven by the higher HDL-C observed with increasing dairy fat intake ${ }^{(25)}$. Significant increases in HDL-C levels have been observed in randomised studies of dairy food supplementation using cheese or probiotic yoghurt in healthy adults ${ }^{(26,27)}$. Sphingolipids from dairy fat and bacterial cell walls are thought to play a role in raising HDL-C, which has been observed in women when supplemented with fermented dairy products ${ }^{(28)}$. Dairy supplementation using probiotic yoghurt is also associated with reductions in TC in healthy, mildly to moderately hypercholesterolaemic individuals, and those with type 2 diabetes, in whom significant reductions in LDL-C were also observed $^{(27,29,30)}$.

The mechanism of the lipid-lowering potential of dairy products is not well understood, but may relate to production processes or to a combination of constituents found in dairy foods. Dairy products fermented by some strains of lactic acid bacteria bind directly to bile acids in the gut thereby interfering with cholesterol absorption; while bifidobacteria species

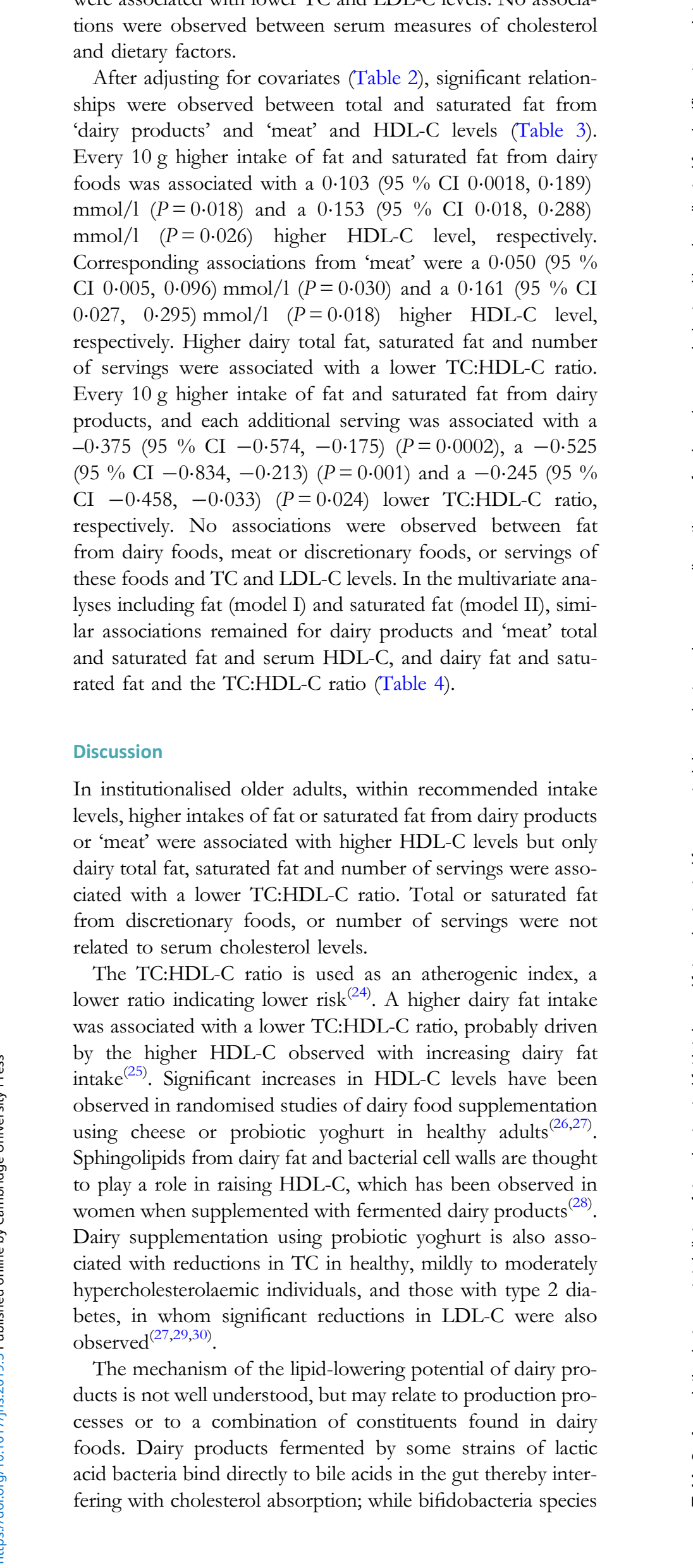

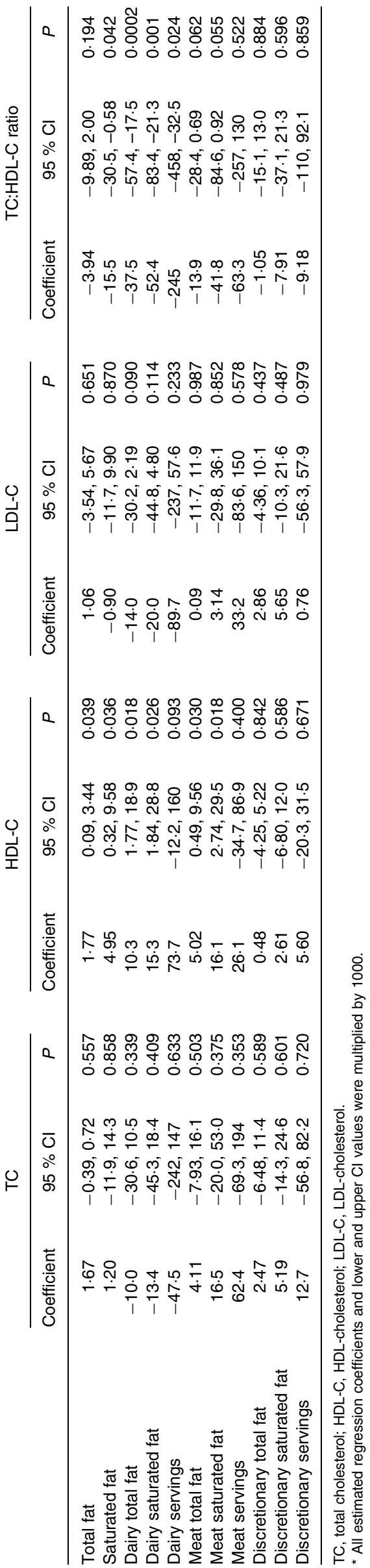


Table 4. Multivariate analysis assessing association between total fat (model I) or saturated fat (model II) and HDL-cholesterol (HDL-C) or total cholesterol (TC):HDL-C ratio, adjusted for age, sex, BMI and cholesterol-lowering medications*

(Coefficients and $95 \%$ confidence intervals)

\begin{tabular}{|c|c|c|c|c|c|c|}
\hline & \multicolumn{3}{|c|}{ HDL-C } & \multicolumn{3}{|c|}{ TC:HDL-C ratio } \\
\hline & Coefficient & $95 \% \mathrm{Cl}$ & $P$ & Coefficient & $95 \% \mathrm{Cl}$ & $P$ \\
\hline \multicolumn{7}{|l|}{ Model I: total fat } \\
\hline Dairy total fat & 0.173 & $0.036,0.310$ & 0.013 & -0.027 & $-0.042,-0.012$ & 0.0003 \\
\hline Meat total fat & 0.106 & $0.018,0.194$ & 0.018 & -0.009 & $-0.019, \quad 0.001$ & 0.085 \\
\hline \multicolumn{7}{|l|}{ Model II: saturated fat } \\
\hline Dairy saturated fat & 0.174 & $0.037,0.312$ & 0.013 & -0.039 & $-0.062,-0.016$ & 0.001 \\
\hline Meat saturated fat & 0.135 & $0.041,0.229$ & 0.005 & -0.029 & $-0.059, \quad 0.0003$ & 0.053 \\
\hline
\end{tabular}

* All variables were standardised to have mean zero and standard deviation of 1.

bind to, and uptake cholesterol particles in the presence of bile salts $^{(13)}$.

Milk, cheese and yoghurt are good sources of $\mathrm{Ca}$, which is known to act as a lipid-soluble salt, binding to fatty acids and bile acids in the small intestine, forming insoluble emulsifications, preventing absorption of fat, resulting in increased faecal fat and bile acid excretion ${ }^{(12,31,32)}$. A meta-analysis of fifteen randomised controlled trials that examined the effect of dairy products (or $\mathrm{Ca}$ ) on faecal fat excretion estimated a $5.2 \mathrm{~g}$ increase in faecal fat excretion with the consumption of about $1200 \mathrm{mg}$ of Ca daily ${ }^{(12)}$. Soerensen $e t ~ a l .{ }^{(33)}$ observed in healthy adult males that the increase in serum TC and LDL-C levels when consuming a high-saturated fat diet were attenuated during a 2 -week milk- or cheese-based diet relative to the isoenergetic control diet, and LDL-C decreased with increasing faecal fat excretion $(r-0.404 ; P=0.002)$.

Whey proteins have been shown to increase postprandial plasma amino acid levels and slow gastric emptying, leading to increased satiety ${ }^{(34)}$. Pal et al. ${ }^{(35)}$ reported a $7 \%$ reduction in both TC and LDL-C compared with baseline, after a 12 -week intervention using $54 \mathrm{~g} / \mathrm{d}$ of whey supplements in eighty-nine overweight and obese individuals.

As participants consumed different combinations and amounts of milk, cheese and yoghurt, the magnitude and direction of changes to HDL-C, LDL-C or TC levels may also be differentially influenced by the diverse fatty acid profiles contained within dairy foods ${ }^{(36)}$. Therefore, the favourable cholesterol-altering effects of milk, cheese and yogurt may be via some, all, or a combination of mechanisms. In addition, the purported anti-inflammatory properties of some constituents of dairy foods, especially fermented dairy produce, may also help to reduce CVD risk ${ }^{(37)}$. However, fermented dairy products were consumed by approximately one-third of older adults in this cohort, so numbers were probably insufficient to enable detection of relationships between the number of servings and fat content of fermented dairy foods and serum cholesterol levels.

A favourable association between consumption of fat from the 'meat' food group and serum HDL-C levels was observed. Despite the varying types of foods in this food group, similar responses to serum cholesterol levels have been observed with consumption of red or white meat. For example, Maki et al. ${ }^{(38)}$, in their meta-analyses of randomised controlled trials investigating changes to serum cholesterol levels in response to beef ('red' meat) compared with poultry/fish ('white' meat) consumption, detected no differences to serum TC, LDL-C or HDL-C levels between the 'red' and 'white' meat types. Others have confirmed this observation ${ }^{(39,40)}$. However, a more favourable increase in serum HDL-C levels has been observed when fatty fish (e.g. cod and salmon) is consumed compared with lean fish and chicken, probably due to their fatty acid profile, but fatty fish is infrequently consumed in institutionalised older adults ${ }^{(41)}$.

Cardioprotective qualities have been reported with the consumption of $n-3$ fatty acids found in $\mathrm{fish}^{(42)}$. Howe et al..$^{(10)}$ reported that, in addition to fish and seafood, meat (red meat, poultry and game) is also a major source of $n-3$ fatty acids (contributing to 48 and $43 \%$ of daily $n-3$ fatty acid intake, respectively). Therefore, any deleterious effect of saturated fats in meat may be offset by its $n$-3 fatty acid content.

Previous dietary recommendations suggested that egg consumption be limited because of the high cholesterol content of eggs; however, recent evidence demonstrated increases in serum HDL-C as well as LDL-C with egg consumption. Moreover, eggs are also a rich source of xanthophyll carotenoids, which have been shown to have anti-inflammatory activities $^{(43-45)}$. The number of servings of foods from the 'meat' food group consumed by residents was within the recommended guidelines of $2-2.5$ servings daily, so within recommended levels these foods had a positive effect on serum HDL-C levels.

There are limitations in this study. First, food intake was recorded on randomly selected days, limiting the ability to investigate the relationship between individual foods within a food group and serum cholesterol levels. Second, participants were of advanced aged. An inverse relationship between serum cholesterol and age in the very old may result from selective survival $^{(46,47)}$. However, given the ageing of the global population, the need for institutionalised care will increase, so these findings indicate that food provision (and consumption) in this setting may influence CVD risk. Furthermore, the observations from this cohort may relate to older adults of a similar age residing in the community as mean dietary dairy product intake in this cohort was compatible with the national average of 1.2 servings daily for those greater than 70 years of age ${ }^{(48)}$.

In summary, within the recommended intake levels, higher intakes of fat from dairy product and 'meat' sources were associated with higher HDL-C levels and higher dairy food 
consumption was associated with a lower TC:HDL-C ratio, which are predictive of a more favourable cardiovascular risk profile.

\section{Conclusion}

In institutionalised older adults, consumption of foods from the dairy product and 'meat' food groups within recommended amounts has the potential to improve intakes of key nutrients from these food groups with limited detriment to cardiovascular health.

\section{Acknowledgements}

We thank dietitians Anishya Gangadharan, Annemarie Murrell, Caryn Batchelor, Deanna Lavanty, Ella Smits, Lexie Griffin, Stephanie Renehan, Samantha Chiodo, Sally Collins, Simone Karafilis, Simone Mastronado and Kako Choi for assisting in data collection, and statistician Leonid Churilov for guidance with analyses.

This work was supported by grants from Dairy Australia (grant number TP 701722), California Dairy Research Foundation, National Dairy Council, Aarhus University Hospital and Danish Dairy Research Foundation, Fonterra Co-operative Group Ltd, Dutch Dairy Association, Dairy Council of California, Dairy Farmers of Canada, the Centre National Interprofessionnel de l'Économie Laitière and the University of Melbourne. This study was executed independently of the grant support. The organisations contributing to the funds had no role in the design and execution of the study, and had no input into the data analyses, interpretation or manuscript preparation.

Author contributions were as follows: study concept and design, S. I.; acquisition of data, Y. L. and S. P.; analysis and interpretation of data, Y. L., S. P., E. S., D. L. H., M. B. and S. I.; draft of the manuscript, Y. L., S. P. and S. I.; critical revision of the manuscript for important intellectual content, E. S., D. L. H. and S. I.

There were no conflicts of interest.

\section{References}

1. World Health Organization (2016) Cardiovascular diseases (CVDs). https://www.who.int/cardiovascular_diseases/en/ (accessed March 2019).

2. Australian Government, Australian Institute of Health and Welfare (2014) Health care expenditure on cardiovascular disease 2008-09. https://www.aihw.gov.au/reports/heart-stroke-vascular-disease/ health-care-expenditure-on-cardiovascular-diseases/contents/tableof-contents (accessed February 2019).

3. Patel SA, Winkel M, Ali MK, et al. (2015) Cardiovascular mortality associated with 5 leading risk factors: national and state preventable fractions estimated from survey data. Ann Intern Med 163, 245-253.

4. Iuliano S, Olden A \& Woods J (2013) Meeting the nutritional needs of elderly residents in aged-care: are we doing enough? J Nutr Health Aging 17, 503-508.

5. Iuliano S, Poon S, Wang X, et al. (2017) Dairy food supplementation may reduce malnutrition risk in institutionalised elderly. $\mathrm{Br} \mathrm{J}$ Nutr 117, 142-147.

6. Woods J, Walker K, Iuliano-Burns S, et al. (2009) Malnutrition on the menu: nutritional status of institutionalised elderly Australians in low-level care. J Nutr Health Aging 13, 693-698.
7. Hegsted DM, McGandy RB, Myers ML, et al. (1965) Quantitative effects of dietary fat on serum cholesterol in man. Am J Clin Nutr 17, 281-295.

8. Michas G, Micha R \& Zampelas A (2014) Dietary fats and cardiovascular disease: putting together the pieces of a complicated puzzle. Atherosclerosis 234, 320-328.

9. Australian Government, Department of Health and Ageing (2015) Australian Guide to Healthy Eating. http://www.eatforhealth.gov. au (accessed February 2019).

10. Howe P, Meyer B, Record S, et al. (2006) Dietary intake of longchain omega-3 polyunsaturated fatty acids: contribution of meat sources. Nutrition 22, 47-53.

11. Zulli A, Lau E, Wijaya BP, et al. (2009) High dietary taurine reduces apoptosis and atherosclerosis in the left main coronary artery: association with reduced CCAAT/enhancer binding protein homologous protein and total plasma homocysteine but not lipidemia. Hypertension 53, 1017-1022.

12. Christensen (2009) Effect of calcium from dairy and dietary supplements on faecal fat excretion: a meta-analysis of randomized controlled trials. Obes Rev 10, 475-486.

13. Pereira DIA \& Gibson GR (2002) Effects of consumption of probiotics and prebiotics on serum lipid levels in humans. Crit Rev Biochem Mol Biol 37, 259-281.

14. Huth PJ \& Park KM (2012) Influence of dairy product and milk fat consumption on cardiovascular disease risk: a review of the evidence. Adv Nutr 3, 266-285.

15. Harsha DW, Lin PH, Obarzanek E, et al. (1999) Dietary approaches to stop hypertension: a summary of study results. DASH Collaborative Research Group. J Am Diet Assoc 99, S35-S39.

16. Siervo M, Lara J, Chowdhury S, et al. (2015) Effects of the Dietary Approach to Stop Hypertension (DASH) diet on cardiovascular risk factors: a systematic review and meta-analysis. BrJ Nutr 113, 1-15.

17. Department of Human Services (Victoria) (2009) Nutrition Standards for Menu Items in Victorian Hospitals and Residential Aged Care Facilities. http://www.health.vic.gov.au/patientfood/ nutrition_standards.pdf (accessed February 2019).

18. Sherwin A, Nowson CA, McPhee J, et al. (1988) Nutrient intake at meals in residential care facilities at the aged: validated visual estimation of plate waste. Aust J Nutr Diet 55, 188-193.

19. Food Standards Australia New Zealand (2015) Nutrient Tables for Use in Australia. http://www.foodstandards.gov.au/science/monitoringnutrients/ausnut/foodnutrient/Pages/default.aspx (accessed March 2019).

20. Auyeung TW, Lee JS, Kwok T, et al. (2009) Estimation of stature by measuring fibula and ulna bone length in 2443 older adults. J Nutr Health Aging 13, 931-936.

21. Gauld LM, Kappers J, Carlin JB, et al. (2004) Height prediction from ulna length. Dev Med Child Neurol 46, 475-480.

22. Mitchell CO \& Lipschitz DA (1982) Arm length measurement as an alternative to height in nutritional assessment of the elderly. J Parenteral Enteral Nutr 6, 226-229.

23. Mensink RP, Zock PL, Kester AD, et al. (2003) Effects of dietary fatty acids and carbohydrates on the ratio of serum total to HDL cholesterol and on serum lipids and apolipoproteins: a meta-analysis of 60 controlled trials. Am J Clin Nutr 77, 1146-1155.

24. Prospective Studies Collaboration, Lewington S, Whitlock G, et al. (2007) Blood cholesterol and vascular mortality by age, sex, and blood pressure: a meta-analysis of individual data from 61 prospective studies with 55,000 vascular deaths. Lancet 370, 1829-1839.

25. McTaggart F \& Jones P (2008) Effects of statins on high-density lipoproteins: a potential contribution to cardiovascular benefit. Cardiovasc Drugs Ther 22, 321-338.

26. Thorning TK, Raziani F, Bendsen NT, et al. (2015) Diets with highfat cheese, high-fat meat, or carbohydrate on cardiovascular risk markers in overweight postmenopausal women: a randomized crossover trial. Am J Clin Nutr 102, 573-581.

27. Sadrzadeh-Yeganeh H, Elmadfa I, Djazayery A, et al. (2010) The effects of probiotic and conventional yoghurt on lipid profile in women. Br J Nutr 103, 1778-1783. 
28. Kiessling G, Schneider J \& Jahreis G (2002) Long-term consumption of fermented dairy products over 6 months increases HDL cholesterol. Eur J Clin Nutr 56, 843-849.

29. Ataie-Jafari A, Larijani B, Alavi Majd H, et al. (2009) Cholesterol-lowering effect of probiotic yogurt in comparison with ordinary yogurt in mildly to moderately hypercholesterolemic subjects. Annals Nutr Metab 54, 22-27.

30. Ejtahed HS, Mohtadi-Nia J, Homayouni-Rad A, et al. (2011) Effect of probiotic yogurt containing Lactobacillus acidophilus and Bifidobacterium lactis on lipid profile in individuals with type 2 diabetes mellitus. J Dairy Sci 94, 3288-3294.

31. Lorenzen J \& Astrup A (2011) Dairy calcium intake modifies responsiveness of fat metabolism and blood lipids to a high-fat diet. Br J Nutr 105, 1823-1831.

32. Lorenzen JK, Jensen SK \& Astrup A (2014) Milk minerals modify the effect of fat intake on serum lipid profile: results from an animal and a human short-term study. Br J Nutr 111, 1412-1420.

33. Soerensen KV, Thorning TK, Astrup A, et al. (2014) Effect of dairy calcium from cheese and milk on fecal fat excretion, blood lipids, and appetite in young men. Am J Clin Nutr 99, 984-991.

34. Hall WL, Millward DJ, Long SJ, et al. (2003) Casein and whey exert different effects on plasma amino acid profiles, gastrointestinal hormone secretion and appetite. Br J Nutr 89, 239-248.

35. Pal S, Ellis V \& Dhaliwal S (2010) Effects of whey protein isolate on body composition, lipids, insulin and glucose in overweight and obese individuals. BrJ Nutr 104, 716-723.

36. Mansson HL (2008) Fatty acids in bovine milk fat. Food Nutr Res 52, 10.3402/fnr.v52i0.1821.

37. Lordan R, Tsoupras A, Mitra B, et al. (2018) Dairy fats and cardiovascular disease: do we really need to be concerned? Foods 7, 29.

38. Maki KC, Van Elswyk ME, Alexander DD, et al. (2012) A meta-analysis of randomized controlled trials that compare the lipid effects of beef versus poultry and/or fish consumption. J Clin Lipidol 6, 352-361.
39. Hunninghake DB, Maki KC, Kwiterovich PO, et al. (2000) Incorporation of lean red meat into a National Cholesterol Education Program Step I Diet: a long-term, randomized clinical trial in free-living persons with hypercholesterolemia. J Am Coll Nutr 19, 351-360.

40. Mateo-Gallego R, Perez-Calahorra S, Cenarro A, et al. (2012) Effect of lean red meat from lamb $v$. lean white meat from chicken on the serum lipid profile: a randomised, cross-over study in women. $\mathrm{BrJ}$ Nutr 107, 1403-1407.

41. Hagen IV, Helland A, Bratlie M, et al. (2016) High intake of fatty fish, but not of lean fish, affects serum concentrations of TAG and HDL-cholesterol in healthy, normal-weight adults: a randomised trial. Br J Nutr 116, 648-657.

42. Kris-Etherton PM, Harris WS \& Appel LJ (2002) Fish consumption, fish oil, omega-3 fatty acids, and cardiovascular disease. Circulation 106, 2747.

43. Clayton ZS, Fusco E \& Kern M (2017) Egg consumption and heart health: a review. Nutrition 37, 79-85.

44. DiMarco DM, Norris GH, Millar CL, et al. (2017) Intake of up to 3 eggs per day is associated with changes in HDL function and increased plasma antioxidants in healthy, young adults. J Nutr 147, 323-329.

45. Geiker NRW, Larsen ML, Dyerberg J, et al. (2018) Egg consumption, cardiovascular diseases and type 2 diabetes. Eur J Clin Nutr 72, $44-56$.

46. Weijenberg MP, Feskens EJ \& Kromhout D (1996) Age-related changes in total and high-density-lipoprotein cholesterol in elderly Dutch men. Am J Public Health 86, 798-803.

47. Volpato S, Zuliani G, Guralnik JM, et al. (2001) The inverse association between age and cholesterol level among older patients: the role of poor health status. Gerontology 47, 36-45.

48. Australian Bureau of Statistics (2016) Australian Health Survey: Consumption of Food Groups from the Australian Dietary Guidelines, 2011-12. Catalogue no. 4364.0.55.012. http://www.abs. gov.au/AUSSTATS/abs@.nsf/DetailsPage/4364.0.55.0122011-12 (accessed March 2019). 